\title{
Cine español entre milenios. Perspectivas de estudio
}

\section{Spanish cinema between millennia. Study perspectives}

\author{
Virginia Guarinos \\ Universidad de Sevilla, España \\ guarinos@us.es \\ https://orcid.org/0000-0002-7270-0087 \\ Jean-Paul Aubert \\ Université Côte d'Azur, Francia \\ Jean-Paul.Aubert@univ-cotedazur.fr \\ https://orcid.org/0000-0002-3775-0214
}

\begin{abstract}
Resumen:
Las dos décadas bisagra que unen el siglo XX al XXI suponen también un punto de inflexión social e histórico que se traduce en cambios y emergencias novedosas en el cine español. Esta presentación reflexiona sobre los aspectos fundamentales de esta cinematografía y los engarza con los artículos que componen el presente monográfico. Tras una contextualización histórica general, se presenta una segunda específica sobre el cine español. Profundizando en él, se aborda la aparición de nuevas generaciones de cineastas, así como de géneros o recuperación/modificación de géneros anteriores. La consolidación y aumento de las mujeres directoras también merecen una mención desarrollada, así como el desarrollo del trabajo de las producciones documentales. Se continúa con la plasmación de la internacionalización del cine español, tanto hacia fuera como hacia dentro, más el papel jugado por las nuevas tecnologías en la era multipantalla. Cierra el artículo la referencia a los públicos y el papel de lo social en la cinematografía española, junto con una breve reseña de los artículos que se encontrarán a continuación.
\end{abstract}

\begin{abstract}
:
The two hinge decades that join the 20th to the 21st century also represent a social and historical turning point that translates into new changes and emergencies in Spanish cinema. This presentation reflects on the fundamental aspects of this cinematography and links them with the articles that make up this monograph. After a general historical contextualization, a second specific one about Spanish cinema is presented. Delving into it, the emergence of new generations of filmmakers is addressed, as well as genres or recovery / modification of previous genres. The consolidation and increase of female directors also deserve a developed mention, as well as the development of the work of documentary productions. The internationalization of Spanish cinema continues, both outward and inward, plus the role played by new technologies in the multiscreen era. The article closes with the reference to audiences and the role of the social in Spanish cinematography, together with a brief review of the articles that will be found below.
\end{abstract}

Palabras clave: Cine español; directores españoles de cine; mujeres directoras de cine; documental cinematográfico; géneros cinematográficos; cine y sociedad.

Keywords: Spanish cinema; Spanish filmmakers; female filmmakers; documentary film; film genres; cinema and society. 
Es imposible presentar esta monografía sobre cine español de nuestro pasado más reciente sin hacer referencia a la situación de dificultad actual, en plena pandemia global, que atraviesa nuestra industria, en un año en el que las salas han estado cerradas, en el que los rodajes han tenido que suspenderse, en el que los guionistas se han visto obligados a reescribir escenas para evitar los contactos, en el que el cine, como la cultura en general, ha sido un sector malherido en una industria nacional ya de por sí maltrecha como es la cinematografía española. Es este también un año en el que la propia ceremonia de los premios Goya se ha reinventado desde la sobriedad que exige esta situación, pero que ha arrojado datos interesantes, como el de la presencia de mujeres. Un 41\% de mujeres propuestas a premios es el mayor número en toda la historia de nuestro cine (Cuenca Suárez, 2021), una cifra que no es más que un síntoma de lo mucho que ha cambiado el panorama cinematográfico en este país. Desde luego ese cambio no se ha producido de forma urgente e involuntaria, como la escasa producción de este año por motivos pandémicos, sino que es fruto de todo un proceso de maduración, cambio y transformación que procede de la época inmediatamente anterior a la que vivimos y cuyas emergencias se produjeron en las décadas inter-milenarias. Hasta llegar a este punto han sido varios los momentos históricos que pueden ser considerados bisagra en el desarrollo evolutivo de nuestra cinematografía: las conversaciones de Salamanca, la emergencia del Nuevo Cine Español de los años sesenta, por ejemplo, o el inicio con la Transición del cine en libertad, puesto que, como es sabido, el cine es signo de su tiempo y sufre y se beneficia de la sociedad de la que nace. En ese sentido, la situación de cambio más reciente es muy probablemente la vivida en el sistema cinematográfico español en el puente entre milenios.

En un momento de sociedad líquida, casi evaporada, como dijera en 1999 Bauman (2003), donde la tecnología nos ha llevado a la forma breve, a la rápida lectura, a la fragmentación voluntaria (y a la obligada), el cine parece haberse vuelto el medio de ficción audiovisual más conservador, más lento en admisión y reflejo de brotes novedosos, probablemente por la magnitud de su 
propio sistema de producción, mucho menos ágil que el televisivo, por ejemplo, y más costoso, ya no económicamente, que también, sino desde el punto de vista del esfuerzo general desde todos los puntos del engranaje de la maquinaria.

En estas coordenadas, la contextualización histórica de España en las dos décadas de producción cinematográfica sobre las que gira esta monografía debe verse relativizada y contemplada como una época de bonanza. Lo que en su momento pudiera haber sido vivido como una época crítica, con la mirada de hoy, se torna, adelgazados los hechos por la distancia temporal, amable para un país que en esos veinte años no sabía hacia donde se encaminaba. El inicio de esta etapa viene marcado por la profunda crisis socialista y el paso al primer gobierno del Partido Popular, con la presidencia de José María Aznar. La ruptura del consenso político y el problema de los coletazos finales del terrorismo vasco marcaron esta legislatura, que finaliza con unas elecciones en puertas cuando se produce un hecho que marca la historia del país: los atentados islamistas en Madrid el 11 de marzo de 2004. Dichos comicios dieron de nuevo el poder al partido socialista con la presidencia de José Luis Rodríguez Zapatero en un clima de crispación política que continúa hasta nuestros días. La política antiterrorista, la Iglesia, los derechos sociales fueron las principales causas de enfrentamiento, además de las reformas estatutarias de algunas autonomías, especialmente en lo referente al Estatuto de Cataluña. En este entramado de falta de resultados políticos, el movimiento ciudadano toma cuerpo y ello genera la aparición y desarrollo de nuevos partidos políticos cada vez con más apoyo entre los electores, como es el caso de Ciudadanos, por la derecha, y Podemos, por la izquierda ideológica. Se inicia, pues, la etapa de quiebra del bipartidismo y las dificultades para generar pactos entre partidos y estructuración de gobiernos.

Si bien la emergencia de nuevos problemas y factores en la política nacional fueron importantes en esta cercana etapa, mucho más lo fue, y así quedó marcado en nuestra Historia, la crisis económica global de 2008. La quiebra de entidades financieras, y la explosión de la burbuja inmobiliaria iniciada en 
EEUU, llega a Europa en 2010. El desempleo se cebó especialmente con dos sectores, el de mujeres y el de jóvenes. La pertenencia de España a la Unión Europea posibilitó que poco a poco el país fuera remontando y recuperándose gracias a las ayudas de los fondos europeos destinados a casi todos los sectores de dinamización económica, en términos generales, siendo conscientes de la existencia de mantenimiento de otros sectores deprimidos.

Crisis política, crisis económica, crisis social podrían haber constituido un triángulo poco propicio para la cultura. No obstante, como en muchas otras épocas y lugares, la cultura siempre se produce y puede considerarse una terapia para la población y un medio necesario de expresión de los sufrimientos, las luchas y las esperanzas. Algunos factores fueron determinantes para el enriquecimiento de nuestro país en este sentido. La multiculturalidad, derivada del aumento de la inmigración, la vuelta a la naturaleza, derivada a su vez de la mirada hacia la España despoblada y comunidades autónomas silenciadas con anterioridad, la inconformidad de las mujeres, el desarrollo y abaratamiento vertiginoso de la tecnología y las redes sociales generaron objetos culturales múltiples, heterogéneos, novedosos, que provocaron un aumento considerable del consumo de ocio. Se puede decir que “se popularizó la cultura, democratizándose en sus diferentes ámbitos una cultura española fuerte, diversa y atractiva tanto para españoles como para extranjeros" (Pereira Castañares, 2020, p. 27).

Además de este cambio en las industrias culturales, el universo de la comunicación, de la ficción en particular, se vio afectado por la proliferación de canales privados y la llegada y consolidación del consumo bajo demanda, lo que inicia un proceso de cambio en los hábitos de los espectadores. En simultaneidad, los géneros del reality, y todas sus variantes, y la ficción seriada nacional inician un camino imparable. Mientras tanto, el cine español consigue logros internacionales, como fueron los óscares de Pedro Almodóvar (2000) y Alejandro Amenábar (2006), por Todo sobre mi madre y Mar adentro respectivamente. Esta internacionalización es solo un síntoma de las condiciones en las que se desarrolla nuestro cine en estas décadas. Desde el 
punto de vista político, la normativa reguladora del sector sufre varios giros y ninguno de ellos verdaderamente ventajoso para el cine. Desde la política de desregulación, la eliminación de la cuota de pantalla, la participación de las televisiones en las producciones, la transición digital en producción y en salas, todos los intentos de leyes recibieron la oposición y resistencia de los sectores por ser consideradas intervencionistas en unos casos y ausentes de protección al sector en otros. La última ley, aprobada en 2007, continúa vigente en la actualidad, mientras los cineastas y sus películas siguen su rumbo centrados en sus historias y sus personajes.

El avance cinematográfico de estas décadas, sin duda, se ha producido gracias a ellos y ellas. La convivencia de varias generaciones de directores españoles otorga una riqueza particular al cine de este periodo. Se encuentran en activo todavía algunos de los representantes de dos de las corrientes más representativas de los años 60 del siglo XX, como el Nuevo Cine Español o la Escuela de Barcelona. Así encontramos estrenos de Mario Camus, Basilio Martín Patino, Joaquím Jordá, Gonzalo Suárez, Jaime Camino, Vicente Aranda, Carlos Saura... Y continúan en plena producción los integrantes del ya no tan joven cine español de la siguiente generación de los años 70, como Gutiérrez Aragón, Bigas Lunas, Jaime Chavarri, Pedro Olea, José Luis Garci, Imanol Uribe, Fernando Colomo, Montxo Armendáriz, José Luis Cuerda, Pilar Miró, Pedro Almodóvar y un largo etcétera. Una representación de estas generaciones puede leerse en el artículo de José Luis Sánchez Noriega, a propósito de la magia y la naturaleza como elementos que representan en nuestro cine algo que sucede en este periodo, como es la desurbanización, la descentralización, centrado en particular en el cine de Gutiérrez Aragón; e igualmente, en relación a la obra estético-cinematográfica de Víctor Erice en el artículo escrito por Fernando Ramos Arenas. Pero a mediados de los 90 irrumpe una nueva generación que marca los éxitos y las inquietudes de la sociedad española entre milenios. A esta generación de cineastas pertenecen Álex de la Iglesia, Fernando León de Aranoa, Alejandro Amenábar, Juanma Bajo Ulloa, Agustín Díaz Llanes, David Trueba, Julio Medem y muchos más. 
Todos ellos conforman un conjunto heterogéneo en intereses temáticos y en estéticas multiformes, responsables de esa riqueza a la que antes se aludía. Como afirman Pérez Morán y Sánchez Noriega, "se trata de una generación caracterizada por la pluralidad de estilos y miradas, desde el cine más personal al más comercial, desde las ficciones más imaginativas a las fórmulas de género, desde el compromiso social a la evasión cinéfila" (2020, p. 45).

De entre todas estas variables, algunas destacan más que otras, por tratarse de emergencias abruptas que se extienden rápidamente entre los creadores. Entre algunas de estas cuestiones interesantes se sitúa el auge de la no ficción, por un lado, no solo entendida como género documental, donde la autoficción, el docudrama, el falso documental o los diarios fílmicos se adivinan como una suerte de cine-ensayo; e igualmente, por otro lado, el metacine, con la proliferación de documentales sobre los propios cineastas o historias ficcionales que recrean las trayectorias de directores o actores, la historia de nuestro propio cine; la recuperación de la memoria histórica también alcanzó al propio entorno cinematográfico español. Los nombres y las obras de Manuel Martín Cuenca, Jaime Rosales, Albert Serra, Pedro Aguilera, José Luis LópezLinares y Javier Rioyo, Javier Espada, Diego Galán, Dunia Ayaso y muchos más dan cuenta de ello.

Por otro lado, la recuperación de la animación, al abrigo del éxito internacional que también se produce por estas fechas de la animación para adultos, supone otro de los elementos destacables en el cine español finisecular. No obstante, el trabajo de las obras de género, más allá del de la comedia, prolíferamente visitada por el cine español en toda su historia, y el thriller, cuenta con el éxito de uno en particular: el terror. El cine de terror de calidad, alejado de la serie B anterior, se despliega en las pantallas españolas con un título como arranque, El día de la bestia (Álex de la Iglesia, 1995), más las obras iniciales de Alejandro Amenábar, a las que siguieron parte de la producción de directores como Guillermo del Toro, Paco Plaza, Jaume Balagueró o Juan Antonio Bayona. Sin olvidar que en el cine español también se hace ciencia ficción, sobre este y otros géneros clásicos o recuperados se habla en los 
artículos de Pérez-Gómez, Raya y López y el de Débora Madrid, entre espacios del horror, vigilancias distópicas y seres de otros mundos, en un afán de internacionalización, gracias a los tópicos de género, de la que se hablará más adelante.

Y como hay cuestiones que difícilmente se pueden abandonar, el cine español también continúa desarrollando el género de recuperación de la memoria del pasado más reciente de nuestra Historia, como reflejo social de una España que consiguió entre polémicas aprobar la ley de Memoria Histórica en 2007. Es interesante resaltar que en esta temática destacan especialmente las películas procedentes de relatos literarios, las adaptaciones, numéricamente muy por encima de las cintas con guion original; si bien, el cine de no ficción también prestó atención al documental histórico de la Guerra Civil y la posguerra, siendo de relevancia el documental de tipo biográfico de personas públicas y desconocidas que desde uno y otro bando de la contienda lucharon, murieron o sobrevivieron a ella. Es en esta etapa cuando el rol de la mujer es enfocado como personaje principal, tanto en ficción como en documental, como queda registrado, a modo de ejemplo sobresaliente, en el caso de Las trece rosas (Emilio Martínez-Lázaro, 2007).

Pero el cine es signo de su tiempo, lo que hace que también se contara con una vena importante de representación de problemas sociales contemporáneos, en especial la inmigración y el terrorismo, con el telón de fondo permanente de la crisis económica. Las historias pequeñas, de desconocidos, domésticas, evidencian la representación de personajes y conflictos comunes a muchos españoles. Espejo del nuevo realismo europeo, entre algunas definiciones, los autores y autoras que dirigieron y escribieron en esta línea podrían englobarse en el "realismo social popular" (Jordan y Allinson, 2005), representado por Icíar Bollaín, Achero Mañas o Benito Zambrano y, sobre todo, Fernando León de Aranoa, con títulos como Familia (1996), Barrio (1998), Los lunes al sol (2002) o Princesas (2005). Parte de esa intimidad, que es Historia, fue el tratamiento del asunto del terrorismo, tabú en buena parte del cine español durante mucho tiempo, con cintas intimistas como Días contados (Imanol 
Uribe, 1994) o Yoyes (Helena Taberna, 1999). La crisis económica y la corrupción política e institucional destapada por ella completan esta senda de cotidianidad del país, con La caja 507 (Enrique Urbizu, 2002) o Grupo 7 (Alberto Rodríguez, 2012), por poner un par de ejemplos entre muchos títulos, mayores y menores. Esta utilización del cine como reflejo de su momento, como testimonio histórico, en este caso de la crisis económica de esta pinza temporal, queda reflejada en la investigación de Víctor Álvarez-Rodríguez, centrada, entre otros autores, en Rosales o Cortés. La presencia entre los españoles del nacimiento de minorías étnicas, religiosas o de procedencia, inmigrantes, también despunta, tanto en personajes de fondo, como en conflictos de la trama principal. Las cartas de Alou (Montxo Armendáriz, 1990), Bwana (Imanol Uribe, 1996), Flores de otro mundo (Icíar Bollaín, 1999), Poniente (Chus Gutiérrez, 2002) van abriendo camino para ello. El personaje en estas y otras facetas es protagonista en esta monografía en los artículos de Ander Goicoetxea Pérez, a propósito de Lucía, en la película $E l$ silencio roto, de Montxo Armendáriz (2011), o el de Gordillo, Toledo y Toscano, sobre personajes inmigrantes, otredad y marginalidad en autores tan dispares como, de nuevo, Armendáriz o León de Aranoa.

Puede parecer insólito, pero hasta llegar a este párrafo son varios los nombres de directoras mujeres españolas. La explicación radica precisamente en otro de los hitos de estas dos décadas, como es la proliferación y consolidación de la mujer en el cine, en puestos creativos, como la dirección o el guion. La nómina de directoras que consiguen consolidar sus carreras aumenta de forma muy contundente, aunque continúe siendo un hecho que son más las mujeres que se quedan en solo una primera dirección de largometraje. De todas las películas estrenadas entre 1999 y 2012, las dirigidas por mujeres solo suponen el 10\%, pero, aun así, es un porcentaje muy superior con respecto a épocas anteriores. Es imposible no referirse a directoras como Icíar Bollaín, Isabel Coixet, Ana Díez, Chus Gutiérrez, Gracia Querejeta y una larga nómina de nuevas directoras. Como afirma Zurian, en 2017 las directoras españolas en activo desde el año 2000 sumaban 93. Los productos fílmicos de estas 
directoras nos alejan del tópico del cine de mujer, encontrándose títulos desde los cánones de género más codificados, hasta grandes producciones, producciones en el extranjero, y, porqué no, temas femeninos, intimismo, marginalidad y educación, otredad, violencia machista o revisión del pasado desde la mirada de mujer, con la valentía de algunas de ellas que incluso se atreven con el documental o con la comedia, como es el caso de Inés París. Esta directora y guionista, además de presidenta de CIMA, nos conduce a cerrar este párrafo sobre las cineastas españolas dejando constancia de los inicios del asociacionismo, como forma de sororidad institucionalizada, de las mujeres cineastas españolas en esta asociación referida, CIMA, un instrumento nunca antes existente que ha traído grandes beneficios y visibilización a este colectivo de nuestra industria. Mirada de género es la que enfoca el artículo sobre mujeres criminales, escrito por Laura Pacheco y Valerio Durán, quienes escriben sobre las cineastas Isabel Coixet y Belén Macías.

Tampoco se puede olvidar que en este periodo hay nuevos directores que desarrollan su filmografía con el hombre como protagonista, pero de un modo divergente al personaje masculino habitual, centrándose en él desde el punto de vista de una nueva masculinidad. Uno de esos casos en Cesc Gay, tratado aquí por Ernesto Taborda-Hernández, que profundiza en su estilema como modelo de autor a partir de la película En la ciudad (2003).

Como ya se ha sugerido en líneas anteriores, llama particularmente la atención el renacer del cine documental o cine de no-ficción durante el periodo contemplado en esta monografía. Este boom de un género tradicionalmente minoritario en la cinematografía española no tiene casi antecedente, salvo, quizás, en contextos muy específicos, durante la Guerra Civil y, luego, durante la Transición. Se concretiza con el estreno en pantalla grande de un número significativo de películas, así como con el interés del público y de la crítica por este cine tantas veces ninguneado. Pues, a pesar de moverse en las márgenes de los grandes circuitos de distribución, algunas películas alcanzan un notable éxito y llegan a cosechar premios prestigiosos en festivales internacionales. Entre los múltiples factores que contribuyen a explicar este fenómeno merece 
una mención especial la fundación en 1998 en la Universidad Pompeu Fabra de Barcelona de un Máster documental de creación que impulsó una auténtica dinámica, instaurando métodos de producción y de realización que favorecieron la eclosión de nuevos autores así como el estreno de algunos documentales importantes. El máster planteó desde su inicio, y con el apoyo significativo de televisiones públicas (en particular la catalana TV3), la posibilidad de diseñar una alternativa al modelo informativo del reportaje televisivo. Por otra parte, contribuyó a establecer o a restablecer filiaciones con algunas figuras tutelares del cine documental como pueden ser Basilio Martín Patino, Víctor Erice o Joaquín Jordá, una figura cuya influencia sobre las jóvenes generaciones no ha sido aún suficientemente valorada. Entre los autores relacionados con el Máster destaca la figura de José Luis Guerin, siendo la película En construcción (2001) uno de los ejemplos más representativos de una nueva línea de documentales determinados a abrir nuevos caminos creativos y a la que se le ha dado el nombre de film-ensayo, una línea en la que se sitúan las obras de otros cineastas exigentes como Mercedes Álvarez (El cielo gira, 2004; Mercado de futuro, 2011) o Isaki Lacuesta (Cravan vs. Cravan -2002-, La leyenda del tiempo -2006-, Los pasos dobles, 2011). Como justo homenaje a estos frutos del cine español documental, resulta de imprescindible lectura el artículo de Sergio Cobo e Irene Liberia sobre Jordá y Guerín en sus obras y en su influencia expandida a otros autores contemporáneos.

El cine documental español se caracteriza por su variedad estilística, la diversidad de sus temas y por su capacidad de ofrecer una visión variopinta de la realidad nacional. Es de destacar, sin embargo, la perspectiva política o ideológica adoptada por un número significativo de proyectos cinematográficos. Indudablemente, durante las dos décadas que nos preocupan en estas líneas, el cine documental fue el que mejor se ajustó a la agenda política y social como si los directores, pese a la diversidad de sus planteamientos y a la heterogeneidad de sus propuestas, tuvieran a bien asumir la realidad del país, una realidad de la que, por su parte, el poder 
político parecía cada día más desconectado. En este sentido, es justo mencionar a La pelota vasca (2003) de Julio Medem, que desempeñó un papel importante al intentar ofrecer, en medio de las polémicas, una radiografía de la situación social y política del País Vasco. Asimismo, películas como El efecto Iguazú (2002) de Pere Joan Ventura, Portman a la sombra de Roberto (2001) de Miguel Martí, La mano invisible (2004) de Isadora Guardia o El astillero (Disculpen las molestias) (2007) de Alejandro Zapico recuperan la tradición de los documentales políticos y sociales, al registrar la memoria y las actividades de los movimientos sociales. Estas son posiblemente las premisas de un cine más puramente político, con películas preocupadas por discutir los defectos y los fallos del sistema democrático español y que parecen anticipar los movimientos ciudadanos surgidos a raíz del $15 \mathrm{M}$. Una película colectiva como Hay motivo (2004), que integra lo documental y lo ficticio, es por tanto significativa del renacer de una manera de hacer cine que se confunde a veces con el activismo político.

Otra novedad en el panorama hispano, ya señalada en líneas anteriores, es la transgresión de las fronteras genéricas habituales entre el cine de ficción y el cine documental. El cine ensayo, el falso documental (Tren de sombras de José Luis Guerin, 1997), el docudrama, los diarios fílmicos (Un instante en la vida ajena de José Luis López-Linares, 2003), el cine epistolario, las autoficciones (Familystrip de Lluís Miñarro, 2010) ponen en tela de juicio las categorías habituales y elaboran nuevos conceptos cinematográficos y audiovisuales que abogan por la hibridez formal y el encuentro entre las disciplinas.

Este afán por inventar nuevas formas expresivas coincide con un periodo de reconfiguración de la industria audiovisual. La revolución digital encauzada por el fenómeno de la digitalización, la diversificación de géneros y formatos, así como la diversidad de los modos de acceso a la obra cinematográfica amenazan con desplazar al cinematógrafo, como dispositivo, a un segundo plano, de ahí que el cine parezca buscarse una segunda vida en los museos y las galerías de arte. La inclusión de películas en colecciones de arte contemporáneo ya se ha convertido en algo habitual y los visitantes de los 
museos se han acostumbrado a contemplar obras pictóricas exhibidas juntas con fragmentos de películas. Este movimiento del cine hacia los museos lo iniciaron en su tiempo algunos autores. Valga como ejemplo el de un director "extraterritorial" como Pere Portabella, cuya permeabilidad a todo tipo de expresión artística favoreció el diálogo entre el séptimo arte y las obras tradicionalmente exhibidas en las galerías de arte. Es así cómo películas del director catalán fueron "expuestas" en 2001 en el Museo de Arte Contemporáneo de Barcelona ("Historias sin argumento", MACBA) y luego en 2008 en el Museu de l'Empordà de Figueras o en el Thyssen-Bornemisza de Madrid en el marco de una exposición dedicada a Joan Miró. José Luis Sánchez Noriega convoca la expresión "cine desplazado" (Sanchez Noriega, 2018, p. 609-617) para describir otro tipo de experiencias como el intercambio de vídeos que supusieron las "correspondencias fílmicas" desarrolladas en 2007 por Víctor Erice y Abbas Kiarotami. Una experiencia iniciada por Jordi Balló y ensayada en el espacio del Centre de Cultura Contemporànea de Barcelona se extendió a otros cineastas y se exportó a otros espacios de arte, algunos de gran prestigio, como el Georges Pompidou en Paris (con el título Todas las cartas. Correspondencias fílmicas). Y como parte de estas preocupaciones, Álex Mendíbil reflexiona en esta monografía sobre el reciclaje y la posmodernidad en el cine digital de Jess Franco, un experimentador adelantado a su tiempo.

Las dos décadas en las que se centra este volumen conforman un periodo de profunda transformación del cine que ha ido convirtiéndose en un arte nómada. En 2008, José Luis Guerin expone en la Bienal veneciana una instalación titulada "Las mujeres que no conocemos". En aquel mismo año 2008, el centro de arte alavés Artium abre sus puertas a las "Miradas sin límite" de cinco jóvenes cineastas que se proponen crear para esta ocasión unas piezas de nueva tecnología musical. Son propuestas estéticas que contribuyen a afirmar la condición híbrida, cambiante e inconclusa del cine que, entrado ya en la era digital, por una parte, diluye las fronteras entre ficción, documental y experimentación y, por otra, entabla un diálogo fecundo 
con otras formas expresivas como pueden ser las series de televisión, los videojuegos o incluso los espectáculos en vivo. En este sentido es preciso traer aquí a colación las propuestas experimentales de autores como Antoni Pinente (Film Quartet/Polyframe - 2006-2008) o Isaki Lacuesta que exploran la capacidad que tiene el séptimo arte de expandirse más allá de sus fronteras naturales. La pluralidad de soportes y de formatos caracterizan la obra polifacética de Isaki Lacuesta, figura de proa de un cine en constante expansión, celebrado tanto en las salas de cines, como en Internet o en las instituciones museísticas. Cortos y largometrajes, instalaciones, espectáculos de teatro y de danza y multimedia con proyecciones desplazan la mirada y multiplican los puntos de vista.

El cine ocupa nuevos espacios, plantea nuevos modos de consumo al mismo tiempo que va ganando nuevos públicos. Esos han sido años de cuestionamiento del cine como forma expresiva homogénea. También han sido años de interrogaciones en cuanto a la realidad de una cinematografía nacional. La determinación de la identidad nacional de un producto cinematográfico se ha vuelto un tema controvertido a la hora de la transnacionalización de la industria y de la globalización de la cultura. Algunos autores de renombre no dudan en trasladar los escenarios de sus películas a países extranjeros. Julio Medem opta por Laponia para rodar Los amantes del círculo polar (1998) y por Italia para filmar Habitación en Roma (2010). En Canadá Isabel Coixet realiza Mi vida sin mí (2003) y en Japón Mapa de los sonidos de Tokio (2009). Quizás sea Alejandro Amenábar el autor más representativo de este fenómeno de globalización que ha ido ganando fuerza a lo largo del periodo bisagra que contemplamos en esta monografía. En su caso, y si pensamos en películas como Tesis (1995), Abre los ojos (1997) o The Others (2001), parece justo hablar incluso de un proceso de americanización de los imaginarios que incluye no solo la elección por parte del director de referentes genéricos y temáticos norteamericanos, sino también el recurso al inglés como lengua de rodaje y un reparto internacional. Sin embargo, mientras algunos directores buscan en la cultura global un hipotético remedio a la relativa falta 
de interés del publico español por las películas caseras, otros autores consiguen éxitos de taquillas precisamente por la imagen a veces hiperbólica que ofrecen de lo hispano (valga como ejemplo el ciclo de los "Torrentes" iniciado en 1998 por Santiago Segura). Se ha utilizado el neologismo "glocal" para definir este proceso complejo que combina la intervención de actores y fenómenos globales y la reafirmación de identidades locales (Pohl \& Türschmann, 2007).

Así de rica e interesante se resume la panorámica sobre el cine español de estas dos décadas, capaz de haber suscitado el interés y la financiación de la Secretaría de Estado de Investigación, Desarrollo e Innovación (Ministerio de Ciencia, Innovación y Universidades) sobre un proyecto de investigación codirigido por las universidades de Sevilla y Complutense de Madrid, con la colaboración de las universidades de Côte d'Azur (Nice), Pontificia de Salamanca, Carlos III de Madrid, La Laguna, París Ouest, Bourgogne, Nanterre y algunas más, bajo el título "Desplazamientos, emergencias y nuevos sujetos sociales en el cine español (1996-2011)". Sirva esta monografía para la profundización académica sobre una época reciente de nuestro cine, que es origen y cimiento del cine de hoy en España.

\section{Referencias bibliográficas}

Bauman, Z. (2003). Modernidad líquida. México: Fondo de Cultura Económica.

Cuenca Suárez, S. (2021). Informe CIMA 2020. La representatividad de las mujeres en el sector cinematográfico del largometraje español. Madrid: Instituto de la Cinematografía y de las Artes Audiovisuales/CIMA. Asociación de Mujeres Cineastas y de Medios Audiovisuales.

Jordan, B. y Allison, M. (2005). Spanish Cinema. Londres: Hodder Arnold.

Pereira Castañares, J. C. (2020). De la ruptura del consenso al impacto de la crisis económica. La España de Azar y Zapatero. En Sánchez Noriega, J.L. (ed.), Cine español en la era digital. Emergencias y encrucijadas. Barcelona: Laertes, 13-30.

Pérez Morán, E. y Sánchez Noriega, J. L. (2020). Panorámica: entre las nuevas pantallas y la polifonía audiovisual. En Sánchez Noriega, J. L. (ed.), 
Cine español en la era digital: emergencias y encrucijadas. Barcelona: Laertes, 31-71.

Pohl, Burkhard y Türschmann, Jörg (2007). Miradas glocales. Cine español en el cambio de milenio. Madrid: Iberoamericana, Frankfurt am Main: Vervuert.

Sánchez Noriega, J. L. (2018). Historia del cine. Teorías, estéticas, géneros. Madrid: Alianza Editorial.

Zurian, F. (ed.) (2017). Miradas de mujer. Cineastas españolas para el siglo $X X I$. Madrid: Fundamentos. 